\title{
FORMAÇÃO DE PROFESSORES: QUALIFICAÇÃO PARA ATENDER CRIANÇAS COM DEFICIÊNCIA INTELECTUAL
}

\author{
FORMACIÓN DEL PROFESORADO: CUALIFICACIÓN PARA CONOCER A NIÑOS \\ CON DISCAPACIDAD INTELECTUAL
}

\author{
TEACHER TRAINING: QUALIFICATION TO MEET CHILDREN WITH \\ INTELLECTUAL DISABILITIES
}

Fabiana Mieko do Nascimento BASHIYO ${ }^{1}$

RESUMO: Este trabalho tem como objetivo destacar a importância e necessidade da formação inicial e continuada de professores para atender crianças com deficiência intelectual e transtornos globais do desenvolvimento nas escolas, principalmente após a lei $\mathrm{n}^{\mathrm{o}} 13.146$, de 06 de Julho de 2015, destinada a assegurar e promover, em condições de igualdade, os direitos das pessoas com deficiência, visando à sua inclusão social e cidadania.

PALAVRAS-CHAVE: Formação de professores. Deficiência intelectual. Inclusão.

RESUMEN: Este trabajo tiene como objetivo destacar la importancia y la necesidad de la formación inicial y continua de los maestros para atender a los niños con discapacidad intelectual y trastornos del desarrollo global en las escuelas, especialmente después de la ley No. 13.146, de 06 de julio de 2015, para garantizar y promover, en condiciones de igualdad, los derechos de las personas con discapacidad, con vistas a su inclusión social y ciudadanía.

PALABRAS CLAVE: Formación del profesorado. Discapacidad intelectual. Inserción.

ABSTRACT: This work aims to highlight the importance and necessity of initial and continuing training of teachers to attend children with intellectual disabilities and global developmental disorders in schools, especially after law No. 13,146, of 06 July 2015, to ensure and promote, under conditions of equality, the rights of persons with disabilities, with a view to their social inclusion and citizenship.

KEYWORDS: Teacher training. Intellectual disability. Inclusion.

${ }^{1}$ Universidade Nove de Julho (UNINOVE), Bauru - SP - Brasil. Bacharel em Turismo e Licenciatura em Pedagoga. E-mail: fabibashiyo@gmail.com 


\section{Introdução}

A formação de professores para atender alunos com deficiência intelectual é um desafio, pois exige uma formação teórica e prática e deve estar nos currículos dos cursos de pedagogia. Nesse sentido, através do estágio curricular obrigatório, observou-se a falta de preparo dos professores para lidar com crianças que possuem algum tipo de deficiência. Notou-se também, que ao invés de serem incluídas, elas estavam sendo excluídas da socialização com as outras crianças e desse modo perdem o seu direito de aprendizagem.

Historicamente, as crianças com deficiência intelectual sempre foram educadas em escolas especiais, porém este quadro se modificou após o inciso III do Art. 208 da Constituição Federal que se refere ao atendimento educacional especializado aos portadores de deficiência, preferencialmente na rede regular de ensino, sendo reforçada, mais tarde, pela Lei de Diretrizes e Bases (Lei 9.394/96) e recentemente assegurada pela Lei n ${ }^{\circ} 13.146$, de 06 de Julho de 2015, que busca promover condições de igualdade a todas as pessoas com deficiência.

Apesar da inclusão ser fomentada por políticas públicas, ela ainda não se configura como uma garantia de aprendizagem para todos as crianças e segundo Glat e Blanco (2015),

[...] uma das principais barreiras para a transformação da política de Educação Inclusiva em práticas pedagógicas efetivas, é a precariedade da formação de professores e demais agentes educacionais para lidar com alunos com significantes problemas cognitivos, psicomotores, emocionais e/ou sensoriais, na complexidade de uma turma regular.

E sem uma formação adequada, muitos profissionais não se sentem preparados para trabalhar com as crianças com deficiência nas salas de aula.

Para que as instituições de ensino consigam atender essas crianças é necessário que os professores tenham uma formação inicial e continuada com princípios na Política de educação inclusiva, porque de acordo com Mazzotta apud Rothstein (1993), "pode parecer cruel, mas a verdade é que um professor incompetente ou mal preparado para a tarefa, acarretará à criança com necessidades educacionais especiais maior mal que a ausência de recursos de educação especial".

É importante as escolas estarem conscientes de que profissionais qualificados dentro da sala de aula são essenciais para promover a inclusão e facilitar o processo de ensinoaprendizagem, caso contrário a Política de educação inclusiva será somente uma teoria e tornará a prática caótica e excludente.

Outro ponto a ser questionado é com relação à presença de auxiliares em sala de aula como estratégia para viabilizar a inclusão de crianças com deficiência intelectual, porque todos 
que possuam necessidades educacionais especializadas como: auxílio para questões motoras, exercícios específicos, adaptações na escrita, apoio para locomoção, higiene e alimentação; precisam de uma pessoa capacitada.

Com o advento da inclusão é comum que classes nas quais estejam matriculadas crianças com deficiências contenham auxiliares. Ainda que a indicação ideal seja a de profissionais da educação, em geral, os auxiliares presentes nas classes de educação infantil ou estão em formação ou não possuem formação na área. Tal fato deve alertar os responsáveis dessa etapa de educação básica sobre os cuidados que se deve ter quanto a atuação de um segundo profissional em sala de aula. E como esses profissionais atuam exclusivamente com as crianças com deficiência e de forma paralela ao professor regente de turma, este procedimento pode impedir o desenvolvimento da autonomia e comprometer a aprendizagem e a construção da identidade da criança em questão. A presença de um segundo profissional em sala de aula é valiosa e pode trazer inúmeros benefícios aos alunos e professores, porém quando malconduzida não agrega vantagens ao desenvolvimento da criança com deficiência (COSTA; RANGNI, 2014).

Portanto, não basta existirem políticas públicas de inclusão quando ainda faltam profissionais qualificados para atender essas crianças com deficiência intelectual. É necessário que os professores, durante a sua formação, tenham acesso a conhecimentos mínimos exigidos para poder lidar com crianças com necessidades educativas especiais. E também quando estiverem atuando nas escolas, estas possam oferecer uma formação continuada ao profissional para que ele continue a se desenvolver e oferecer um ensino de qualidade para esses alunos incluídos.

\section{Educação especial e políticas na perspectiva de inclusão}

O direito social à educação foi uma conquista, como apontam Silva e Jurdi (2019, p. 843), é assegurado pela Constituição Federal de 1988, tal como o direito de crianças com deficiência de frequentarem a rede ensino pública, como norteia a Lei de Diretrizes e Bases da Educação Nacional (Lei nº. 9304/96) da LDB (BRASIL, 2010a). Dessa forma, como apontam as autoras, tanto a educação de pessoas com deficiência quanto a educação infantil passaram a ser reorganizadas e aprimoradas. Nesse ponto, é importante salientar que a educação especial, em certa medida, traz dificuldades na relação entre professor e aluno (SILVA; JURDI, 2019, p. $843)$. 
Em grande medida, isso é resultado do baixo número de matrículas desses alunos nas escolas, o que resulta em uma experiência limitada em vários lugares. É importante pontuar que a maior parte das pesquisas se sustenta na relação entre normalidade e anormalidade, como colocam Freitas e Baptista (2019, p. 793), em relação a normalidade, entende-se tendo como base o pensamento de Canguilhem (2000) e Focault (2002), associando-se ao pensamento sistêmico de Gregoru Bateson (1993). A articulação entre normal e anormal gera, portanto, conceitos como o de Transtorno de Déficit de Atenção com Hiperatividade - TDAH. Essas premissas também são reafirmadas por Vitta, Araujo e Giroto (2019, p. 808), elas apontam que isso faz parte de uma construção discursiva que é carregada de valores sociais, históricos e ideológicos retratados nos discursos. Assim, quando há essa normalização, há também o processo de estigmatização dos processos distintos da apropriação do conhecimento, como, nas palavras das autoras, "sintomas de doenças, num processo de naturalização das diferenças e individualização de questões que perpassam a apropriação da linguagem escrita". Desse ponto de vista, se considerarmos que os processos educacionais têm se organizado na perspectiva da educação inclusiva (em que a universalização do acesso à educação, tal como a igualdade de direitos tem privilégios (BRASIL, 2008)), é de se esperar a heterogeneidade do público-alvo, assim como, das formas de apropriação do conhecimento (VITTA; ARAUJO; GIROTO, 2019, p. 809).

\title{
Formação de professores e educação especial: da formação inicial à continuada
}

\begin{abstract}
Ao considerarmos que a creche, que abarca o berçário, tem papel predominantemente assistencialista, corremos o risco de olhar para as crianças através de qualidades sociais que levam à exclusão, deixando de oferecer-lhes condições que permitam melhorar sua história, a partir da função educativa e pedagógica da escola (VITTA; MOURO; SGAVIOLI, 2019, p. 830).
\end{abstract}

A partir disso, as autoras reforçam a importância de manter esforços no sentido de otimizar as atividades oferecidas, no sentido de estimular um desenvolvimento global, no qual o empoderamento de crianças passa a ser uma importante bandeira (VITTA; MOURO; SGAVIOLI, 2019, p. 830).

Para Silva e Saigh (2019, p. 843) a ideia de Pacheco (2012) reforça que a educação inclusiva é um produto histórico de uma época de realidades educacionais contemporâneas e que é um ato coletivo à medida que "ultrapassa os muros da escola" propondo uma grande transformação cultural e social. 
Salto e Carneiro (2019, p. 858) fazem um estudo de caso sobre a educação infantil que elucida bem essa questão da inclusão: “[...]Consequentemente, é mais fácil para o aluno o desejo de construir a sua aprendizagem, além de permitir, também, a construção das mais diversas habilidades" (CAPPELINI; RODRIGUES, 2009).

Nesse sentido, para acontecer a inclusão, também deve haver uma mudança no corpo docente para que depois exista uma atitude nas crianças. Quando há a valorização do aluno dentro das suas limitações, há também o desenvolvimento de condições que contribuam na diminuição da ansiedade e da depressão (MACEDO, 2008, p. 135 apud SALTO; CARNEIRO, 2019, p. 860). A mudança no professor começa a partir do momento em que ele perde o medo de lidar com o diferente, como demonstram as autoras em diversas passagens relatadas em seu artigo. Segundo as autoras, o despreparo também faz crer que os docentes acreditam precisar de "alguém de fora" para trazer a experiência necessária no tratamento de alunos que precisam de educação especial (SALTO; CARNEIRO, 2019, p. 860).

\section{Atuação do professor no atendimento à criança com deficiência intelectual e transtornos do desenvolvimento}

A fase pré-escolar, portanto, é uma das mais importantes no desenvolvimento da educação especial a medida em que é nesse contexto que se desenvolvem as relações sociais tanto dos adultos com as crianças, como das crianças com outras crianças. Em um caso específico, Oliveira e Araujo (2019, p. 879-880) acentuam essa ideia ao debaterem sobre resultado do acompanhamento pedagógico de uma criança com síndrome de Down na préescola. Elas colocam que "a participação da criança nas mais distintas atividades propostas [...] indicaram o envolvimento e interações dialógicas entre essa criança e seus pares" (OLIVEIRA; ARAUJO, 2019, p. 880).

Nesse contexto, as autoras colocam que quando a professora estava atenta e se planejava antecipadamente nas atividades, a criança-alvo ficava mais disposta a participar e se envolver com a atividade. Os recursos mesmo que sejam adaptados, são os principais responsáveis pela prática inclusiva, como é pontuado: é o seu uso que indicará a sua função e, portanto, não basta apenas organizar o meio se a qualidade de interação com esse meio não for provisionada (OLIVEIRA; ARAUJO, 2019, p. 880).

A partir disso, fica evidente que os maiores problemas e desafios na educação especial estão alojados no seio não só das políticas que norteiam esses projetos, mas também na mentalidade do docente que tem função fundamental no processo de aprendizagem do aluno. 
Correia e Baptista (2018, p. 724), apresentam algumas questões importantes nesse contexto. Citando Santos (2004) e Caiado (2009), os autores colocam que a "ética do cuidado" poderia ajudar em muito na diminuição da lógica competitiva e desumana que acaba afetando pessoas com necessidades especiais. Assim, condições suficientes para educação inclusiva (SILVA; SOUZA; FALEIRO, 2018, p. 744).

Santana, Castro e Lima (2018, p. 760) apontam que a condução de políticas inclusivas é movimentada com base numa atuação assistencialista/caritativa (FREITAS, 2009; MAZZOTTA, 2011 apud CASTRO; LIMA, 2018, p. 760), preocupando-se com o conforto e bem-estar dessas pessoas.

\section{Considerações finais}

Fica claro, portanto, a importância de trabalhar no sentido de melhorar - e ampliar - o acesso e o espaço a educação especial no Brasil. Nesse sentido, as diversas iniciativas têm papel fundamental. Projetos como o "Todos Nós em Rede” (MANTOAN; BAPTISTA, 2018, p. 768) tem destaque à medida que partem da seguinte questão: "seria possível fazer uma educação continuada mais flexível que os cursos de especialização e formação continuada a distância e ancorada nos problemas do cotidiano das professoras?" (MANTOAN; BAPTISTA, 2018, p. 768). A partir disso, o projeto tenta trazer o trabalho colaborativo, unindo educação e internet, denominado design participativo (BARANAUSKAS; ROCHA, 2003 apud MANTOAN; BAPTISTA, 2018, p. 768).

Diante do exposto, reforça à necessidade de uma formação de forma mais abrangente para que o professor possa atuar na Educação Especial, e como se demonstra neste estudo atender crianças com deficiência intelectual de forma mais humana possível e fazer sua inclusão na sociedade e no grupo escolar. E a formação continuada deve ser incentivada junto aos professores bem como na gestão escolar.

\section{REFERÊNCIAS}

BRASIL. Lei no 13.146, de 6 de julho de 2015. Institui a Lei Brasileira de Inclusão da Pessoa com Deficiência (Estatuto da Pessoa com Deficiência). Brasília, DF, jul. 2015. Disponível em: http://www.planalto.gov.br/CCIVIL_03/_Ato20152018/2015/Lei/L13146.htm. Acesso em: 06 abr. 2019. 
CAMILO, C. Inclusão: o espaço dos auxiliares. Disponível em:

https://novaescola.org.br/conteudo/1692/inclusao-o-espaco-dos-auxiliares. Acesso em: 09 de abril 2019.

CORREIA, G. B.; BAPTISTA, C. R. Política nacional de Educação Especial na perspectiva da Educação Inclusiva de 2008. Revista on line de Política e Gestão Educacional, Araraquara, v. 22, n. esp. 2, p. 716-731, dez., 2018. DOI: 10.22633/rpge.unesp.v22.nesp2.dez.2018.11905.

COSTA, M da P. R. da; RANGNI, R. de A. Educação especial na educação infantil. São Carlos: Pedro e João Editores, 2014.

FREITAS, C. R. de; BAPTISTA, C. R. Mais rápidas que a escola: crianças referidas como hiperativas no contexto escolar. Revista Ibero-Americana de Estudos em Educação, Araraquara, v. 14, n. esp. 1, p. 791-806, abr., 2019. E-ISSN: 19825587. DOI: 10.21723/riaee.v14iesp.1.12207.

GIROTO, C. R. M.; ARAUJO, L. A. de; VITTA, F. C. F. de. Discursivização sobre "doenças do não aprender" no contexto educacional inclusivo: o que dizem os professores de Educação Infantil? Revista IberoAmericana de Estudos em Educação, Araraquara, v. 14, n. esp. 1, p. 807-825, abr., 2019. EISSN: 1982-5587. DOI: 10.21723/riaee.v14iesp.1.12208.

GLAT, R.; BLANCO, L. de M. V. Educação especial no contexto de uma educação inclusiva. In: GLAT, R. (Org.). Educação inclusiva: cultura e cotidiano escolar. 2 ed. Rio de Janeiro: Ed. Sette Letras, 2015.

MANTOAN, M. T. Eglér; BAPTISTA, M. I. Sampaio Dias. Inovar para fazer acontecer: como estamos fortalecendo redes de apoio à educação inclusiva. Revista on line de Política e Gestão Educacional, Araraquara, v. 22, n. esp. 2, p. 763777, dez., 2018. ISSN: 1519-9029. DOI: 10.22633/rpge.unesp.v22.nesp2.dez.2018.11911.

MAZZOTTA, M. J. da S. Trabalho docente e formação de professores de educação especial. São Paulo: E.P.U, 1993.

MILANEZ, S. G. Costa; OLIVEIRA, A. A. S.; MISQUIATTI, A. R. N. Atendimento Educacional Especializado para alunos com Deficiência Intelectual e Transtornos Globais do Desenvolvimento. Marilia: ABEU, 2013.

OLIVEIRA, J. P.; ARAUJO, M. A. A participação de uma criança com síndrome de Down em práticas pedagógicas na Educação Infantil. Revista IberoAmericana de Estudos em Educação, Araraquara, v. 14, n. esp. 1, p. 869-882, abr., 2019. EISSN: 1982-5587. DOI: 10.21723/riaee.v14iesp.1.12212.

PEREIRA DOS SANTOS, M.; BARREIROS DE LIMA, C.; SALVINO, M. N. de A., Inclusão no Ensino Superior pela Lente Omnilética: Um foco na formação docente. Revista on line de Política e Gestão Educacional, Araraquara, v. 22, n. esp. 2, p. 825-839, dez., 2018. ISSN: 1519-9029. DOI:10.22633/rpge.unesp.v22.nesp2.dez.2018.11915.

RAMOS, M. A Educação Inclusiva e a Deficiência Mental. Disponível em: http://www.profala.com/arteducesp185.htm. Acesso em: 07 de maio de 2019. 
SALTO, Mariana Picchi; CARNEIRO, Relma Urel Carbone. A concepção docente em uma experiência de Educação Infantil inclusiva: um estudo de caso. Revista Ibero-Americana de Estudos em Educação, Araraquara, v. 14, n. esp. 1, p. 855-868, abr., 2019. E-ISSN:

19825587. DOI: 10.21723/riaee.v14iesp.1.12211.

SANTANA, M. S. R.; CASTRO, R. M. de; LIMA, E. A. de. A produção acadêmico-científica do Programa de Pós-Graduação em Educação da UNESP/Marília-SP e a Política Pública Nacional de Educação Especial no Brasil: aspectos históricos. Revista on line de Política e Gestão Educacional, Araraquara, v. 22, n. esp. 2, p. 748-762, 2018. E-ISSN:1519-9029. DOI: 10.22633/rpge.unesp.v22.nesp2.dez.2018.11910.

SILVA, C. S. B. da; JURDI, A. P. Experiências e apontamentos de professoras de creche sobre inclusão escolar. Revista Ibero-Americana de Estudos em Educação, Araraquara, v. 14, n. esp. 1, p. 842-854, abr., 2019. E-ISSN: 1982-5587. DOI:

10.21723/riaee.v14iesp.1.12210.

SILVA, L. C.; SOUZA, V. A.; FALEIRO, W. Uma década da política nacional de educação especial na perspectiva da educação inclusiva. Revista on line de Política e Gestão

Educacional, Araraquara, v. 22, n. esp. 2, p. 732-747, dez., 2018. DOI:

10.22633/rpge.unesp.v22.nesp2.dez.2018.11906.

TENENTE, L. Total de alunos com deficiência em escolas comuns cresce 6 vezes em 10 anos. Disponível em: https://g1.globo.com/educacao/noticia/total-de-alunos-especiais-emescolas-comuns-cresce-6-vezes-em-10-anos.ghtml. Acesso em: 07 de maio 2019.

VITTA, F. C. Fr. de; MOURO, M. M.; SGAVIOLI, A. J. R. Atraso no desenvolvimento e inclusão: a opinião de profissionais do berçário. Revista Ibero-Americana de Estudos em Educação, Araraquara, v. 14, n. esp. 1, p. 826841, abr., 2019. E-ISSN: 1982-5587. DOI: 10.21723/riaee.v14iesp.1.12209.

\section{Como referenciar este artigo}

BASHIYO, Fabiana Mieko do Nascimento. Formação de professores: qualificação para atender crianças com deficiência intelectual. Temas em Educ. e Saúde, Araraquara, v. 15, n. 1, p. 3845, jan./jun., 2019. e-ISSN 2526-3471. ISSN 1517-7947. DOI: 10.26673/tes.v15i1.12769

Submetido em: 02/02/2019

Aprovado em: 30/04/2019 